\title{
Immediate Implants- A Novel Intervention in Implant Dentistry- A Case Report
}

\author{
Dr. Tazeen Dawood ${ }^{1}$, Dr. Hassan Sadek ${ }^{2}$, \\ ${ }^{1}$ Assistant Professor, Department of Periodontics, College of Dentistry, Jazan University, Jazan, Saudi Arabia. \\ ${ }^{2}$ Professor, Department of Oral and Maxillofacial Surgery and Implantology, College of Dentistry, \\ Jazan University, Jazan, Saudi Arabia.
}

\begin{abstract}
Dental implants are no longer an enigma but now a reality as we have walked out of the arena of single speciality treatments to multi- disciplinary approaches aiming at the rehabilitation of patients with missing teeth. From the past decade the golden standard of implant protocol has been replaced by new and more novel interventions owing to the advances in clinical techniques and expansion of biomaterials which has lead to a new era of modern implant dentistry, which promises better rehabilitation of missing teeth both functionally and aesthetically, shorten treatment periods, better ossteointegration of implants and a high implant success rate. This case report highlights atraumatic tooth extraction followed by immediate implant placement. A 30 year male patient was reffered to the oral implantology unit of College of Dentistry Jazan university, Saudi Arabia, with a fractured root canal failure upper left posterior tooth which required extraction followed by immediate implant placement. Clinical and radiographic examination revealed a root canal treated, grossly destructed tooth 25.Atraumatic extraction was done followed by immediate implant placement. Follow up was done every month for 4 months after which the abutment was placed, and later final prosthesis, implant showed good ossteo -integration with no signs of peri-implantitis.
\end{abstract}

Keywords: immediate implant, ossteointegration, fresh extraction socket

\section{Introduction}

According to the international congress of implantology glossary, implants placed at the time of extraction of the tooth are known as immediate implants. Immediate placement of a dental implant in an extraction socket was initially described by Schulte and Heimke in 1978[1] .Reductions in the number of surgical interventions, a shorter treatment time, an ideal three dimensional implant positioning, the presumptive preservation of alveolar bone at the site of the tooth extraction and soft tissue aesthetics have been claimed as the potential advantages of this treatment modality .The morphology of the implant site, the presence of periapical pathology, the absence of keratinized tissue, thin tissue biotype and lack of complete soft tissue closure over the extraction socket have been reported to adversely affect immediate implant placement. Indications for immediate implant placement include trauma not affecting the alveolar bone, decay without purulence, endodontic failure, severe periodontal bone loss, residual root and root fracture[2,3,4].

\subsection{Factors to be considered while placing immediate implants}

\subsection{Pre-surgical implant site}

The morphology of maxillary anteriors including premolars exhibit thinner labiobuccal bony lamella than palatal bone, but the mandibular lingual alveolar bone is thinner than labial bone. These factors should be considered in selecting the most appropriate angulation of the pilot drills, which in turn determine the longitudinal axis of the implant site to avoid perforation of alveolar bone plates .[5]

\subsection{Prevention of cortical bone lamella}

It is important to minimize bone trauma during surgical removal of the tooth. After extraction, the socket should be thoroughly degranulated by careful curettage, choice of the implant diameter and size should be performed on the basis of the orofacial and mesiodistal diameters of the alveolus[6,7,8]. De Wijs et al (1997) concludes that immediate implant placement is only indicated when the major part of the labial cortical wall is still intact.[9]

\subsection{Immediate implant placement}

Implants must be placed 3.0 to $5.0 \mathrm{~mm}$ beyond the apex in order to gain a maximal degree of stability and as close as possible to the alveolar crest level $(0$ to $3.0 \mathrm{~mm})$.In cases of multi-rooted teeth, the implant can be placed in the interseptal bone or in the maxillary palatal socket [10]. 


\subsection{Crestal bone-to-implant gap}

Schulte and coworkers[1] emphasized that a gap between the bone and the implant, requires the use grafting and a barrier membrane, however, it should be considered when the jumping distance is more than $1 \mathrm{~mm} \cdot[10,11]$

\subsection{Inflamation and purulence}

If any purulent exudate is present during the course of surgery, exhibiting any signs of active inflammation or infection, antibiotic therapy is initiated priorly and implant placement is delayed. According to some authors the presence of an asymptomatic apical granuloma or cyst is not necessarily a contra indication to an immediate insertion of an implant,[12]

\subsection{Primary closure is most important.}

\subsection{Temporary restoration post implant placement}

The literature advocates the wearing of a prosthesis not earlier than 2 weeks post-implant placement to prevent early trauma to the gingival site above the implant . The area should be left without pressure during the entire healing period by using an appropriate temporary restoration.

\subsection{Implants and occlusion}

It is essential that the occlusion is adjusted in such a way that the implant is just out of contact with the opposing tooth at a position of lightest occlusal contact of the opposing arches. Occlusal adjustment should also ensure that the implant-supported crown does not bear excessive loads in lateral or protrusive excursions of the mandible.

\section{Case Presentation}

A 30 year old systemically healthy ,moderately built and nourished male patient was reffered to oral implantology unit of College of dentistry, Jazan University Saudi Arabia, with a chief complaint of a fractured root canal failure upper left posterior tooth which required extraction followed by immediate implant placement. Clinical and radiographic examination revealed a fractured root canal treated grossly destructed tooth in relation to\# 25.This case report highlights atraumatic tooth extraction, attempting to preserve as much bone as possible followed by implant placement in relation to\# 25.Post surgical instructions were given, antibiotics were prescribed to the patient. Suture removal was done after 1 week. Follow up was done every month for 4 months after which the abutment was placed followed by final prosthesis, implant showed good ossteo-integration with no signs of peri implantitis.

\section{Investigations}

Pre-surgical evaluation was primary accomplished by OPG to evaluate any peri apical pathology in relation to 25 , and also to determine the length of the root "Fig1". Blood investigation was done to rule out any blood disorders.

\section{Surgical Procedure}

The surgical procedure was carried out under local anaesthesia (2\% mepivacaine with 1:100.000 epinephrine). Crevicular incisions were made around 24,25,26 followed by vertical releasing incisions made distal to first premolar and first molar "Fig2,3." Mucoperiosteal flaps were elevated."Fig".4. Osteoplasty was performed around the grossly destructed crown to create a tunnel to enable enough grip for atraumatic tooth extraction by round bur and hand piece "Fig." 5 . Tooth extraction was done preserving the buccal and lingual bone in relation to 25."Fig."6. tooth socket was throughly examined for any pathology .(figure6) . paralleling pin was placed to determine the direction of implant axis,"Fig."7 implant placement was done in relation to 25"Fig"8. mucoperiosteal flaps were approximated by non resorble synthetic 4-0sutures"Fig".9.Immediate post operative panorama was taken to check the implant directions"Fig.10" Post surgical instructions were given along with $1 \mathrm{~g}$ augmentin, $600 \mathrm{mg}$ brufen and mouthwash for a week. Patient was recalled after one one week for suture removal, follow up was done every month and after four months abutments were placed,"Fig."11 followed by final prosthesis after 1 month."Fig."12. 


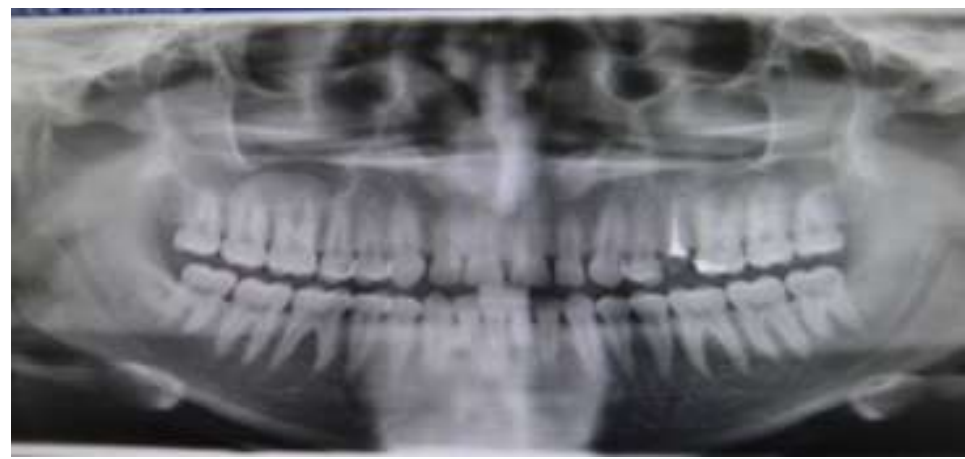

No.1 Pre-operative OPG

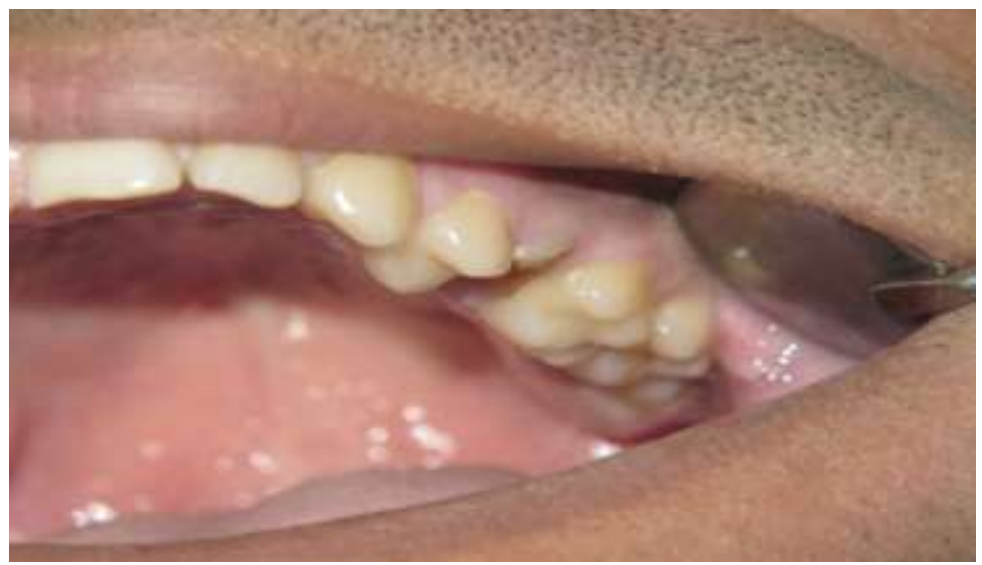

Figure 2 pre operative intra- oral view

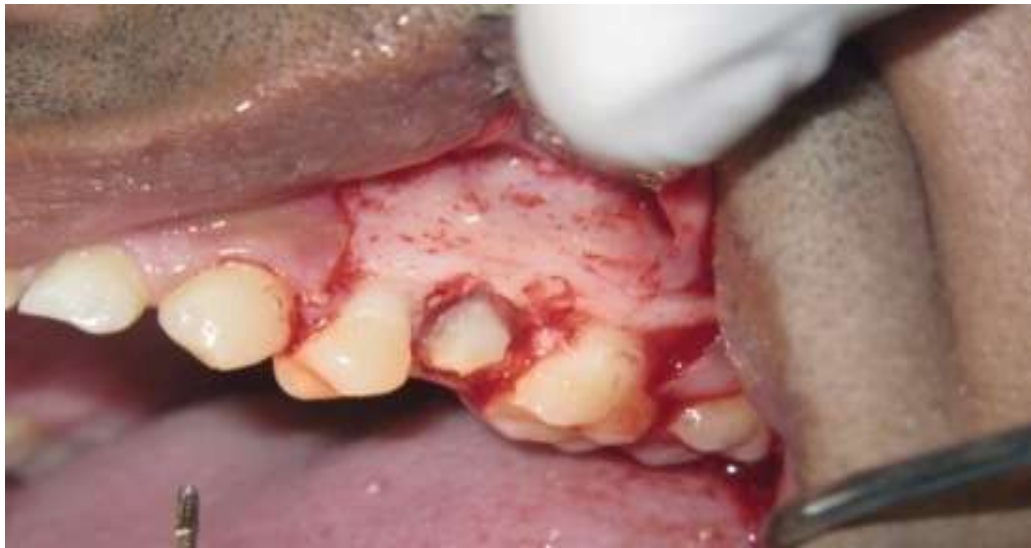

Figure 3 vertical releasing incisions made along with muco- periosteal flap elevation 




Figure4, osteoplasty performed by round bur

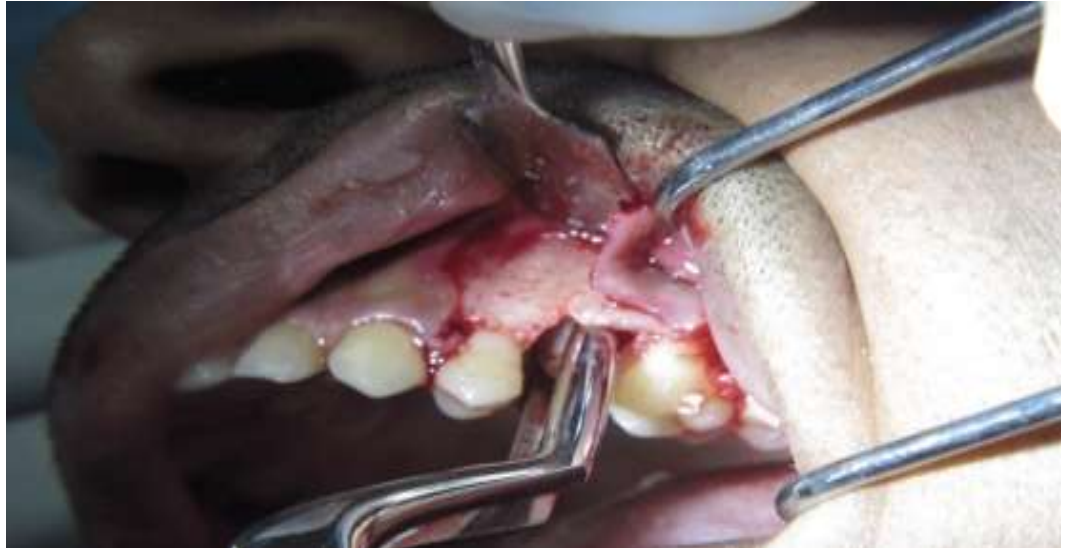

Figure 5 atraumatic extraction done



Figure 6 implant site prepared

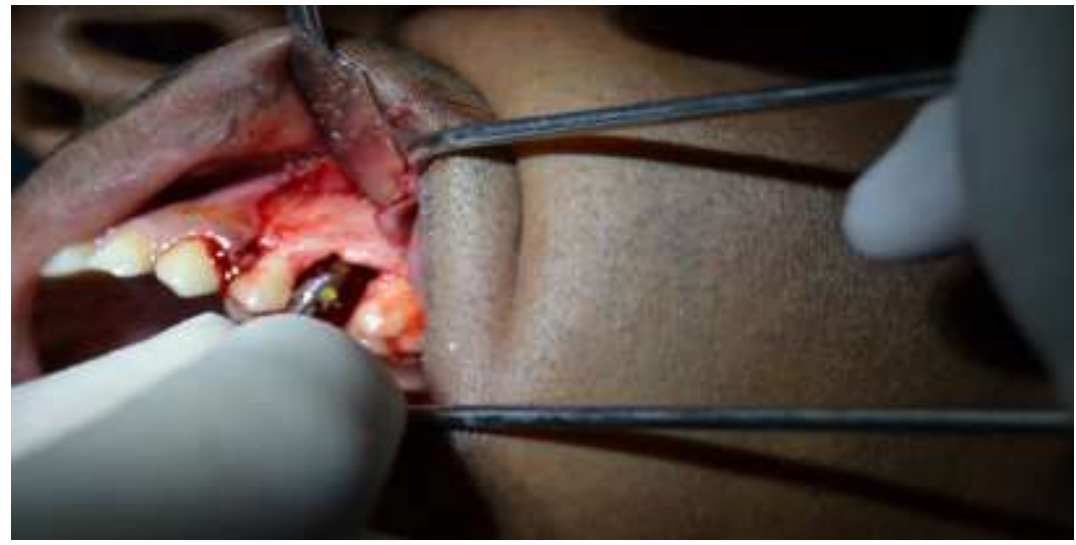

Figure7 paralleling pin placed to check implant axis 




Figure8 implant placed

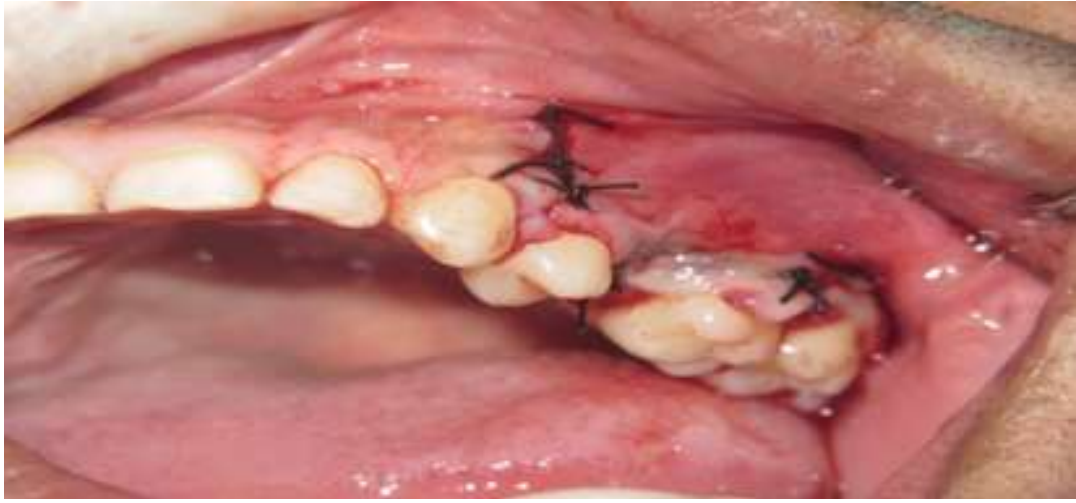

Figure9 flaps approximated and sutures placed

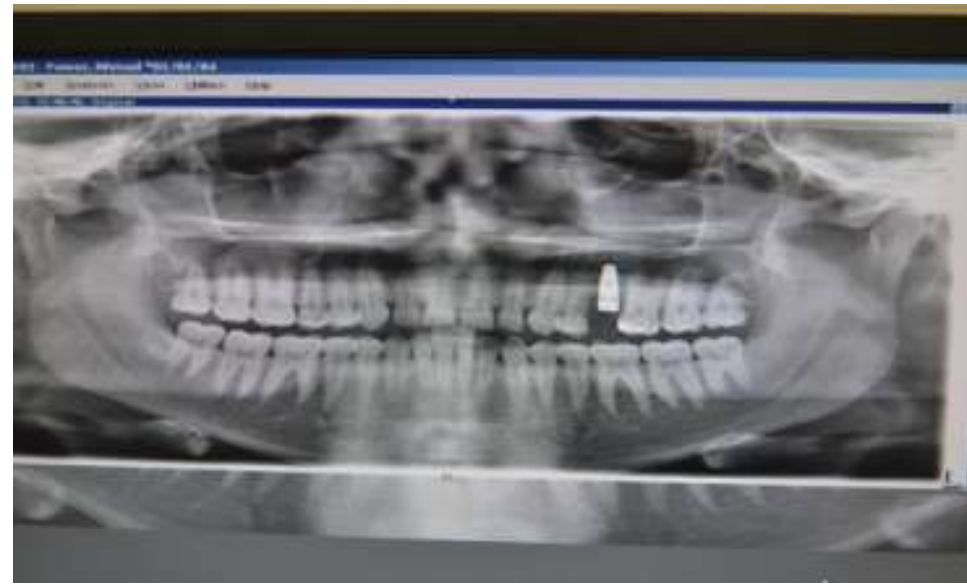

Figure 10 immediate post operative OPG

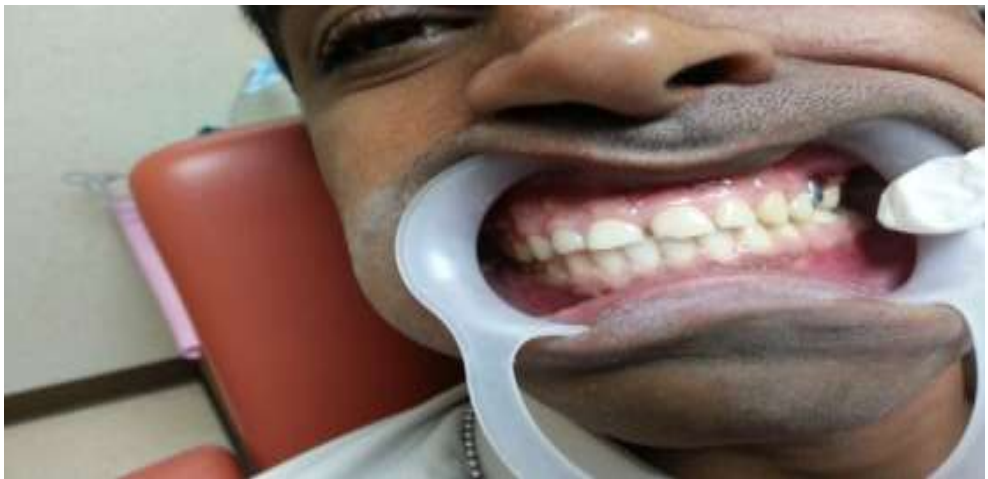

Figure 11 abutment placed after 4 months 


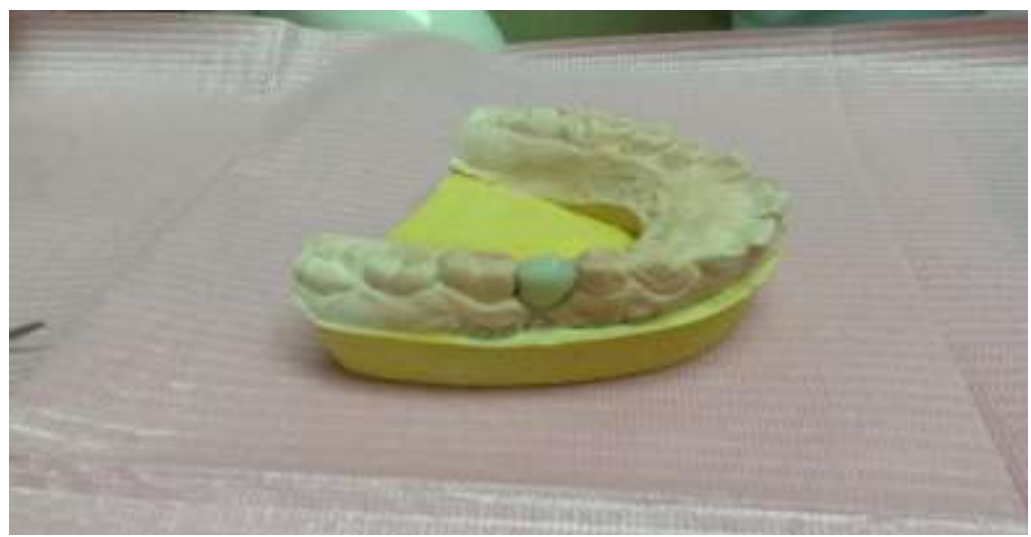

Figure12 final prosthetic procelin crown

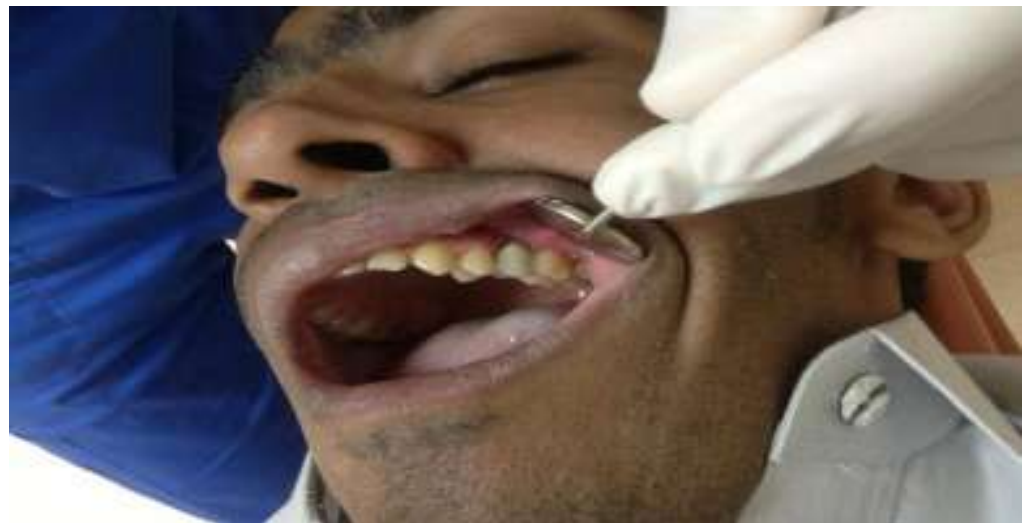

Figure 13.final prosthetic procelin crown placed

Implant showed full integration during the follow-up period . Clinical evaluation showed a normal periimplant probing depth with no signs of bleeding on probing. Implant healed with cover screw exposed. "Fig 12) The panoramic X-ray after implant placement showed the right implant axis and good ossteointegration After 4 months implant were loaded with a provisional screwed crown. After soft-tissue healing, implant was loaded with cemented fixed single crown supported by pre-formed titanium abutment "Fig." 13. The patient was included in a recall program that provides a clinical control every 4 months and radiographic control every 6 months.

\section{Discussion}

There are four different types of immediate implant placement techniques namely type 1 , defined as "implant placement immediately following tooth extraction, type 2 defined as placement of the implant following complete soft tissue coverage of the socket (typically 4 to 8 weeks postsurgery). Type 3 defined as implant placement "following substantial clinical and/or radiographic fill of the socket (typically 12-16 weeks)." Type 4 defined as implant placement in the healed site (typically more than 16 weeks . Quirynen et al.(2007) focused their review on immediate versus delayed implant placement, several studies have been conducted to evaluate the primary implant stability of immediate versus delayed implant placement.[13]

According to systemic review by Ortega-Martínez J et.al, ,[2012)[14], Chen et.al 2004, immediate implants have predictable results with several advantages over delayed implant placement. Polize et.al 2000 [15] demonstrated that the cumulative implant survival rate after 5 years of loading had not changed and was $92.4 \%$ in the maxilla and $94.7 \%$ in the mandible. No difference in failure rates were seen between the groups. CalvoGuirado et al.(2009)[16], Lang et al.(2007)[17] compared primary stability of immediately placed implants of tapered versus cylindrical design using RFA. No statis-tically significant differences were found between both treatment approaches. Several studies have been conducted by Gelb et al,[18] Mendsdorff-Pouilly et al 1994[19] shwartz arad et al2000.[20], Gomez-Romon etal 2001[21]Wagenberg \& Ginsberg 2000[22]who have placed more than 200 immediate implants followed by guided bone regeneration through the use of bone grafting materials like autogeneous bone, hydroxyapatite and allogenic bone material with or without guided tissue regenerative membranes and have reported a implant success rateof 92 to $95 \%$ over a follow up period of 2-3 years. Rosenquist \& Grenliie et.al [23] ,Becker etal1998 [24] ,Grunder et .al 1999,[25] Biancho \& Son Filippo 
20O4[26] and Krump\&Barnettl[27] have evaluated about 100 implants without using any bone regenerative material following immediate implant placement after tooth extraction.

In this case report we have not used any bone grafting material after implant placement, as the jumping distance between the implant and bone was less than $1 \mathrm{~mm}$, however bone grafts, with or without membranes should be placed in extraction sockets if the jumping distance is more than $2 \mathrm{~mm}$. Chen ST, Beagle J, et.al 2009[28],Esposito M, et .al 2008[29] conducted clinical procedures regarding the: bone augmentation techniques for dental implant treatment. They concluded that the augmentation procedures appear not to influence vertical resorption on the facial bone.[30] Vanden Bogaerde Let.al 2016 [31]in a case-series study compared the Stability of Implant with Two Different Surfaces Placed in Fresh Extraction Sockets and Immediately Loaded. They concluded that the hydrophilic and rougher test implant was more resistant to immediate loading and showed a significantly higher stability than the smoother control implant after 12 weeks.

\section{Conclusion}

Immediate implant placement following tooth extraction might be a viable alternative to delayed placement. However, it requires a careful case selection and a specific treatment protocol because it is a very sensitive technique and more difficult to execute than a conventional protocol.

\section{References}

[1]. Schulte W, Kleineikenscheidt H, Linder K, Schareyka R. The Tubingen immediate implant in clinical studies. Dtsch Zah- narztlZ 1978; 5:348-359.

[2]. Chen ST, Wilson TG. , Hammerle CH. Immediate or early placement of im-plants following tooth extraction: review of biologic basis, clinical procedures, and out-comes. Int J Oral Maxillofac Implants. 2004;19 Suppl:12-25.

[3]. Schulte W, d'Hoedt B, Axmann D, Gomez G. The First 15 years of the Tuebinger implant and its furtherdevelopment to the FRIALIT®-2 system. Sonderdruck, Z Zahnärztl Implantologie, VIII;2, 1992.

[4]. Gomez-Roman G, Schulte W, d'Hoedt B, Axman-Krcmar D. The FRIALIT®-2 implant system: Five-yearclinical experience in single-tooth and immediately postextraction applications. Int J Oral MaxillofacImplants 1997;12:299-309.

[5]. Schulte W, d’Hoedt B. 13 Jahre Tübinger Implantat aus FRIALIT® - Weitere Ergebnisse. , Z ZahnärztlImplantologie, IV, 167-173, 1988.

[6]. Quayle AA, Cawood J, Howell RA, Eldridge DJ, Smith GA. The immediate or delayed replacement of teethby permucosal intraosseous implants: The Tübingen implant system. British Dental Journal; Vol 166, 10,365-370.

[7]. Quayle AA, Cawood J, Smith GA, Eldridge DJ, Howell RA. The immediate or delayed replacement of teeth bey permucosal intraosseous implants: The Tübingen implant system. Part 2: Surgical and restorativetechniques. British Dental Journal; Vol 166, 11, 403-410.

[8]. Lazzara RJ. Immediate implant placement into extraction sites: Surgical and restorative advantages. Int JPerio Rest Dent 1989; Vol 9, 5, 333-344

[9]. De Wijs FL, Cune MS. Immediate labial contour restoration for improved esthetics: A radiographic study onbone splitting in anterior single-tooth replacement. Int J Oral Maxillofac Implants; 12:686-696, 1997.

[10]. Schwartz.-.Arad D, Chaushu G. The ways and wherefores of immediate placement of implants into freshextraction sites. A literature review. J Periodontol 1997;68:915-923.

[11]. Babbush CA. Guidelines for implant placement after immediate extraction. Acedemy of Osseointegration,Academy News Vol 9, 4, 1998.

[12]. Shirota T, Schmelzeisen R, Neukam F, Matsui Y, Ohno K, Michi K. Immediate insertion of two types ofimplants into vascularized bone grafts used fro mandibular reconstruction miniature pigs, Oral Surg OralMed Oral Pathol 1994;77,222-231.

[13]. Quirynen M, Van Assche N, Botticelli D, Berglundh T. How does the timing of implant placement to extraction affect outcome? Int J Oral Maxillofac Implants. 2007;22 Suppl:203-23.

[14]. Ortega-Martínez J1, Pérez-Pascual T, Mareque-Bueno S, Hernández-Alfaro F, Ferrés-Padró E. Immediate implants following tooth extraction. A systematic review. Med Oral Patol Oral Cir Bucal. 2012 Mar 1;17(2):e251-61.

[15]. Polizzi G1, Grunder U, Goené R, Hatano N, Henry P, Jackson WJ, Kawamura K, Renouard F, Rosenberg R, Triplett G, Werbitt M, Lithner B.Immediate and delayed implant placement into extraction sockets: a 5-year report. Clin Implant Dent Relat Res. 2000;2(2):93-9

[16]. Calvo-Guirado JL, Ortiz-Ruiz AJ, Lopez-Mari L, Delgado-Ruiz R, Mate-Sanchez J, Bravo Gonzalez LA. Immediate maxillary restoration of single-tooth im-plants using platform switching for crestal bone preservation: a 12-month study. Int J Oral Maxillofac Implants. 2009;24:275-81.

[17]. Lang NP, Tonetti MS, Suvan JE, Pierre Bernard J, Botticelli D, Fourmousis I. Immediate implant placement with transmucosal healing in areas of aesthetic priority. A multicentre randomizedcontrolled clinical trial I. Surgical outcomes. Clin Oral Implants Res. 2007;18:188-96.

[18]. Gelb DA. Immediate implant surgery: three year retrospec- tive evaluation of 50 consecutive cases. Int J Oral Maxillofac Implants 1993; 8:388-399

[19]. Mensdorff-Pouilly N, Haas R, Mailath G, Watzek G. The immediate implant: a retrospective study comparing the dif- ferent types of immediate implantation. Int | Oral Maxillo- fac Implants 1994; 9:571-578.

[20]. 20.Schwartz-Arad D, Grossman Y, Chaushu G. The clinical effec- tiveness ol implants placed immediately into fresh extraction sites of molar teeth. J Periodontol 2000; 71:839-844

[21]. Gomez-Roman G, Kruppenbacker M, Weber H, Schulte W. Immediate post extraction implant placement with Root- analog stepped implants: surgical procedure and statistical outcome after 6 years. Int J Oral Maxillofac Implants 2001; 16:503-513.

[22]. Wagenberg BD, Ginsberg TR. Immediate implant place- ment on removal of the natural tooth: retrospective analysis of 1,081 implants. Compendium 2001; 22:399-410.

[23]. Rosenquist B, Grenthe B. Immediate placement of implants into extraction sockets: implanl survival. Int I Oral Maxillo- fac Implants 1996; 11:205-209. 
[24]. Becker BE, Becker W, Ricci A. Geurs N. A prospective clini- cal trial of endosseous screw-shaped implants placed at the time of tooth extraction without augmentation. J Periodon- tol 1998; 69:920-926.

[25]. Grunder U, Polizzi F, Coene R, et al. A 3-year prospective multicenter follow-up report on the immediate and delayed immediate placement of implants. Int J Oral Maxillofac Implants 1999; 14:210-216.

[26]. Biancho AE, San Filippo F. Single tooth replacement by immediate implant and connective tissue graft: a 1-9 year clinical evaluation. Clin Oral Implants Res 2004; 15:269-277

[27]. Krump JL, Bamett BG. The immediate implant: a treatment alternative. Int I Oral Maxillofac Implants 1991; 6:19-23.

[28]. Schwartz-Arad D, Chaushu G. The ways and wherefores of immediate placement of implant placement of implants into fresh extraction sites: a literature review. J Periodontol 1997; 68:915-923.

[29]. Chen ST, Beagle J, Jensen SS, Chiapasco M, Darby I. Consensus statements and recommended clinical procedures regarding surgical techniques. Int J Oral Maxillofac Implants. 2009;24 Suppl:272-8.

[30]. Esposito M, Grusovin MG, Kwan S, Worthington HV, Coulthard P. Interven-tions for replacing missing teeth: bone augmentation techniques for dental implant treatment. Cochrane Database Syst Rev. 2008:CD003607.

[31]. Vanden Bogaerde L1, Sennerby L2.A Randomized Case-Series Study Comparing the Stability of Implant with Two Different Surfaces Placed in Fresh Extraction Sockets and Immediately Loaded. The results from the present study indicated that the hydrophilic and rougher test implant was more resistant to immediate loading and showed a significantly higher stability than the smoother control implant after 12 weeks. int J Dent. 2016; 2016:8424931. 